IJADR

International Journal of Alcohol and Drug Research

The Official Journal of the Kettil Bruun Society for Social and Epidemiological Research on Alcohol

doi: $10.7895 /$ ijadr.277

IJADR, 2020, 8(2), 61-68

ISSN: 1925-7066

\title{
Price and income elasticities for alcohol in Sri Lanka
}

\author{
Håkan Leifman ${ }^{1}$ and Björn Trolldal ${ }^{1,2}$ \\ ${ }^{1}$ Karolinska Institutet, Department of Clinical Neuroscience, Stockholm, Sweden \\ ${ }^{2}$ Swedish Council for Information on Alcohol and Other Drugs (CAN), Sweden
}

\begin{abstract}
Aims: To study the effect of changes in income as well as prices of beer and arrack, on alcohol sales in Sri Lanka during the period 1981-2017.

Design: The analyses were conducted by means of ARIMA time series analysis for arrack and beer separately.

Measures: Yearly data on the sales of beer and arrack in the entire country were used. National GDP figures were used as a proxy measure of income, and yearly price data for arrack and beer were from Colombo, the largest metropolitan area in the country.
\end{abstract}

Results: No short-term effects of changes in price or income were found on sales. However, changes in the price of beer were significant, with a lag structure, which implies a delayed effect of price changes on the sales of beer. A significant cross-price effect of changes in the price of beer on arrack sales was found as well.

Conclusions: Sales of alcohol in Sri Lanka are not affected by price changes to the same extent as in high income countries. Most likely, the explanations will be found in the different drinking cultures between Sri Lanka and these countries.

\section{Introduction}

A body of published research has shown the effectiveness of alcohol taxation and pricing in affecting alcohol consumption and related harm (Anderson, Chisholm, \& Fuhr, 2009; Babor et al., 2010; Elder et al., 2010; Wagenaar, Salois, \& Komro, 2009; Wagenaar, Tobler \& Komro, 2010). For that reason, several countries actively employ alcohol taxation as an important policy measure.

The significance of price (affected by taxation) as a determinant of alcohol consumption follows traditional economic theory. In a review of 112 studies, primarily from high-income countries, Wagenaar and colleagues (2009) found that the mean price elasticity was -0.46 for beer, -0.69 for wine, -0.80 for spirits, and -0.51 for total sales. In another review, Elder and colleagues (2010) observed similar elasticity values. An estimated elasticity shows how much a one percent increase in price affects sales in percentage terms.

Although numerous studies have been conducted, few of them have been from low- and middle-income countries (LMIC). A few studies have been conducted in India but none with time series data and all covered only parts of India (Kumar, 2017). In a cross-sectional study from five states in 2014, alcohol prices were found to be negatively associated with demand for alcoholic beverages ( -0.14 for spirits, -0.33 for beer and -0.46 for local sprits) (Kumar, 2017).

A systematic review by Sornpaisarn, Shield, Cohen, Schwartz, and Rehm (2013), identified twelve studies with relevant information on alcohol price and/or taxation and resulting effects on sales in LMIC. Meta-analyses on the estimates revealed an average price elasticity of -0.50 for beer, -0.79 for other alcoholic beverages (including wine and spirits), and -0.64 for total sales. One of the 12 studies comprised data from 19 countries, including Sri Lanka (Selvanathan \& Selvanathan, 2005). The price elasticity for total sales in Sri Lanka was positive, but nonsignificant. However, no beverage-specific analyses were conducted, and the time period was short: 1984-1996. In 2011, Sri Lanka achieved the status of a middle-income country (UNDP, 2012).

In Sri Lanka, arrack and beer are the two predominating beverages accounting for about $90 \%$ of total sales annually throughout the study period. (Arrack is a fermented and distilled liquor.) In the present study, the effect of changes in beverage-specific prices as well as income on sales of arrack and beer was estimated during the period 1981-2017. 
A study of the effects of price and income on beveragespecific sales of alcohol in Sri Lanka is also of interest for reasons other than the lack of previous studies. One reason is that its alcohol culture differs from that in many western countries. Drinking is almost exclusively undertaken by men. According to the legislation dating back to the 1950 s and further underlined in 1979, women are not allowed to purchase alcohol in retail shops, nor to work in establishments that sell alcohol without prior approval (Excise Notification, 1951; 1955; 1979). During a 12month period, $2 \%$ of women consumed alcohol, according to a survey conducted during 2014-2015. The corresponding figure for men was $50 \%$. Twenty-five percent of all men drank once a month or more often and approximately $15 \%$ at least once a week (Ministry of Health, Nutrition and Indigenous Medicine, 2015). Thus, the sales data mainly reflect purchases by men who are weekly consumers. How such a group of consumers react to price and income changes in an alcohol culture that is totally different from that in high-income countries is unknown.

Sri Lanka has a significant public health burden due to alcohol misuse even though the total number of consumers and per capita consumption are rather low (approximately 4 liters per inhabitant aged 15 or above (WHO, 2018; Leifman, 2019). Around 75\% of all deaths are due to noncommunicable diseases and alcohol misuse has been identified as one of the top five factors contributing to this disease burden. Harmful use has also been identified as a major risk factor contributing to drunk driving accidents, domestic violence, mental illness, self-harm and suicide (see Nugawela, Lewis, Szatkowski and Langley, 2017).

Another reason for studying the effects of alcohol prices on sales in Sri Lanka is the lack of studies in countries with very high alcohol prices. In 2016, the price for a bottle of arrack $(750 \mathrm{ml}, 33.5 \%$ alcohol by volume $[\mathrm{ABV}])$ was approximately 1,300 Rupees (8.4 USD). The price of beer was 200 Rupees (1.30 USD, $625 \mathrm{ml}, 4.8 \%$ ABV). These prices should be related to the mean income per capita which was 16,400 Rupees (105 USD) per month (Department of Census and Statistics, 2018a). In relative terms, alcohol prices in Sri Lanka are exceptionally high. Despite high prices and relatively low prevalence of alcohol consumption, Sri Lanka experiences significant alcohol-related harm and continues to seek to understand whether price can be used as a lever to reduce alcohol consumption and associated problems.

\section{Methods}

\section{Price Series and Taxation}

The prices of beer and arrack reported on in this study cover the period 1981-2017. For beer, the original series refers to the nominal retail prices (in Rupees) of one of the most popular brands - Lion Lager (4.8\% ABV). Regarding arrack, the average retail prices of the two most common brands (Arrack Special and Arrack Coconut) were used.

The original series prices were converted into an index and transformed into real prices by means of the consumer price index (CCPI), (Department of Census and Statistics $2018 \mathrm{~b}$ ). If the price changed during a year, the weighted average was used. The prices refer to retail prices in Colombo, Sri Lanka's capital and biggest metropolitan area. However, the retail prices were almost identical throughout the country, but these data were only available from 1991. In 2016 and 2017, alcohol taxation accounted for $48-49 \%$ of the price of beer, and for $63-64 \%$ of the price of arrack. Figure 1 shows the series of real (indexed) prices for beer and arrack for the years 1981-2017.

\section{Figure 1}

Real Prices (Indexed) for Beer and Arrack, 1981-2017

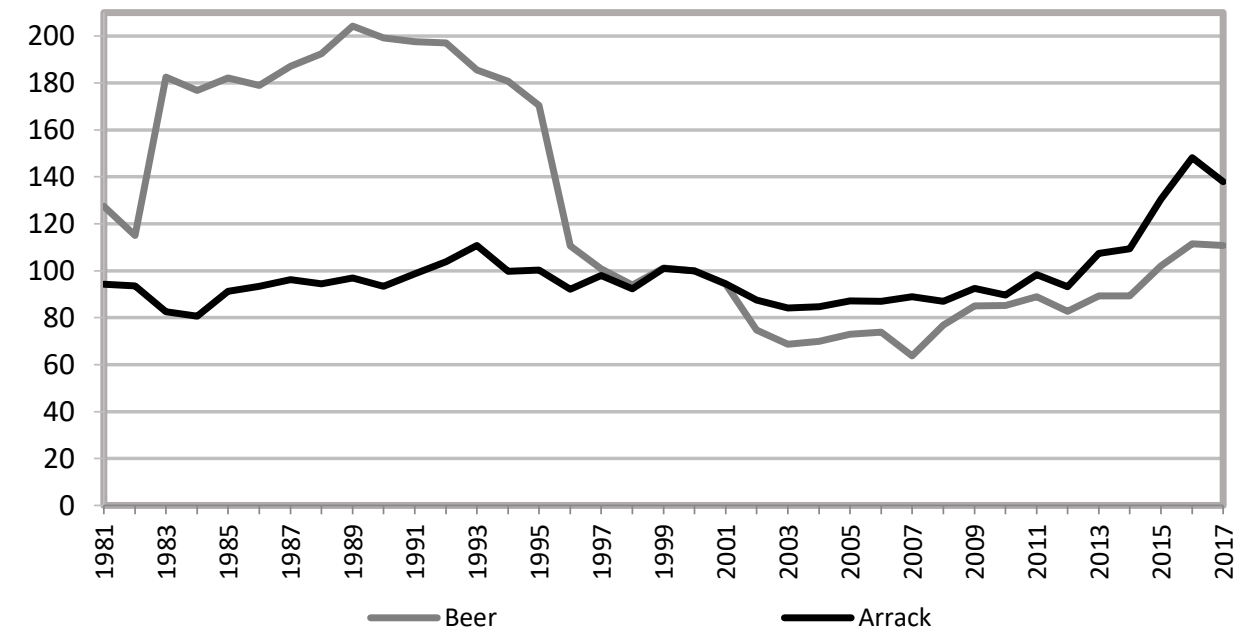

Note: Index year 2000=100. Beer: Colombo prices for Lion lager; Arrack: Colombo average prices for Arrack Special and Arrack Coconut. Source: Department of Census and Statistics (2018b). 


\section{Income Series}

Annual data on Gross Domestic Product (GDP), per capita, was used as an indicator for income (World Bank Data Base, 2018). Mean income per capita assessments in household income and expenditure surveys (Department of Census and Statistics, 2018a) are not carried out annually and cannot be used in the analyses but are included for trend comparison. Both series are shown in Figure 2. The trends are similar until 2007. Thereafter, GDP increased substantially more $(69 \%)$ than the mean income (44\%). There could be several reasons for this mismatch, which is beyond the scope of this study.

\section{Figure 2}

Gross Domestic Product and Mean Income Per Capita According to Household Surveys, in Real Terms

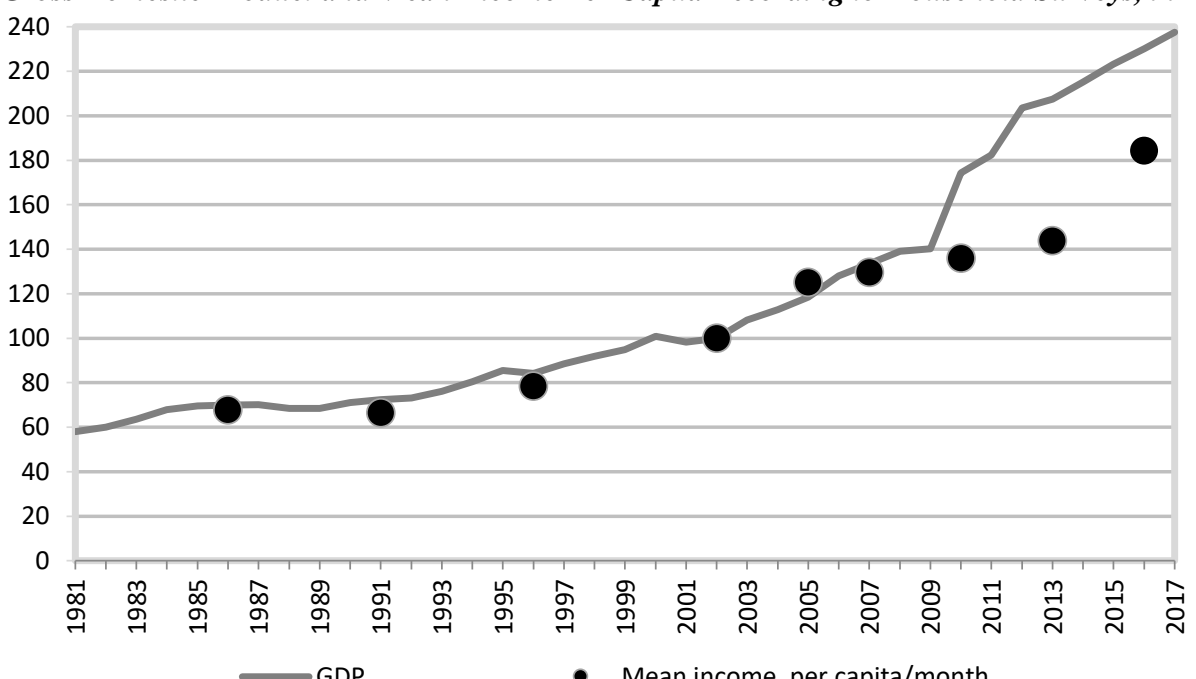

Note: Index year 2000=100. Sources: Gross Domestic Products (GDP): World Bank Data Base (2018); Mean income: Department of Census and Statistics, (2018a).

\section{Sales of Alcohol}

The sales data, published yearly by the Excise Department, cover all main alcoholic beverages sold at onand off-licensed premises. The volumes were converted into pure $(100 \%)$ alcohol per beverage and divided by the total number of inhabitants aged 15 or above. The analyses were focused on arrack and beer. In 2017, 95\% of all arrack and $72 \%$ of all beer was sold at off-licensed premises. Corresponding percentages for previous years could not be obtained. The trends in sales of all beverages 1981-2017 are shown in Figure 3.

Figure 3

Recorded Alcohol Sales per Beverage and Total 1981-2017

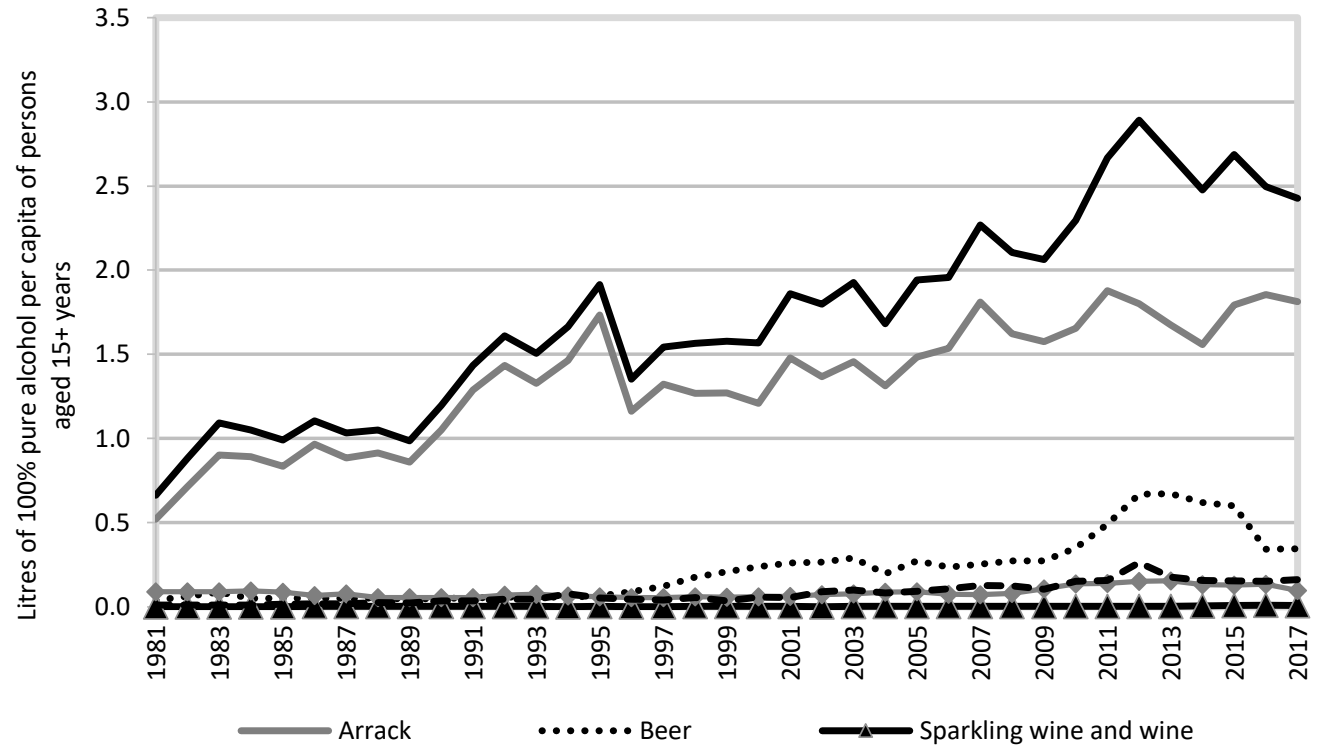

Note: Sum of sales at on- and off-licenced premises. Source: Excise Department of Sri Lanka (2017). 
Arrack was the predominating beverage, in liters of pure alcohol sold in Sri Lanka (Figure 3). During 2010-2017, it accounted for about $70 \%$ of the total sales. However, the long-term trend was toward a lower share of arrack and an increased share of beer. After 2014, the sales of beer, in pure alcohol, have decreased whereas other beverages have remained approximately constant. In 2015, beer accounted for $22 \%$ and for $14 \%$ of total sales in 2017 .

The sales data (recorded consumption) do not include unrecorded consumption, comprising in Sri Lanka, mainly the home-produced spirit "kassippu". The volume of unrecorded consumption is widely discussed in Sri Lanka, but is still largely unknown (Leifman, 2019). WHO's Global Information System on Alcohol and Health estimated the unrecorded consumption to be on average
1.5 liters annually during 2009-2011 and 1.6 liters during 2015-2017. This would comprise over a third of total annual consumption (estimated to be somewhat lower than 4 liters 2009-2011 and slightly higher than this in 20152017 (WHO 2014; WHO 2018)). These figures have been criticized and other national data suggest unrecorded levels are well below 0.5 liters (Leifman, 2019). In any case, the consumption trends suggested by the recorded sales do not change significantly if these estimates of unrecorded consumption are added (Leifman, 2019).

Figures $4 \mathrm{a}$ and $4 \mathrm{~b}$ show the real price and sales of beer and arrack for the period 1981-2017. The prices have varied substantially, due to frequent (often annual) changes in excise duty rates, and inflation.

\section{Figure 4a}

Real Price Index of Beer and Sales of Beer (Left) 1981-2017

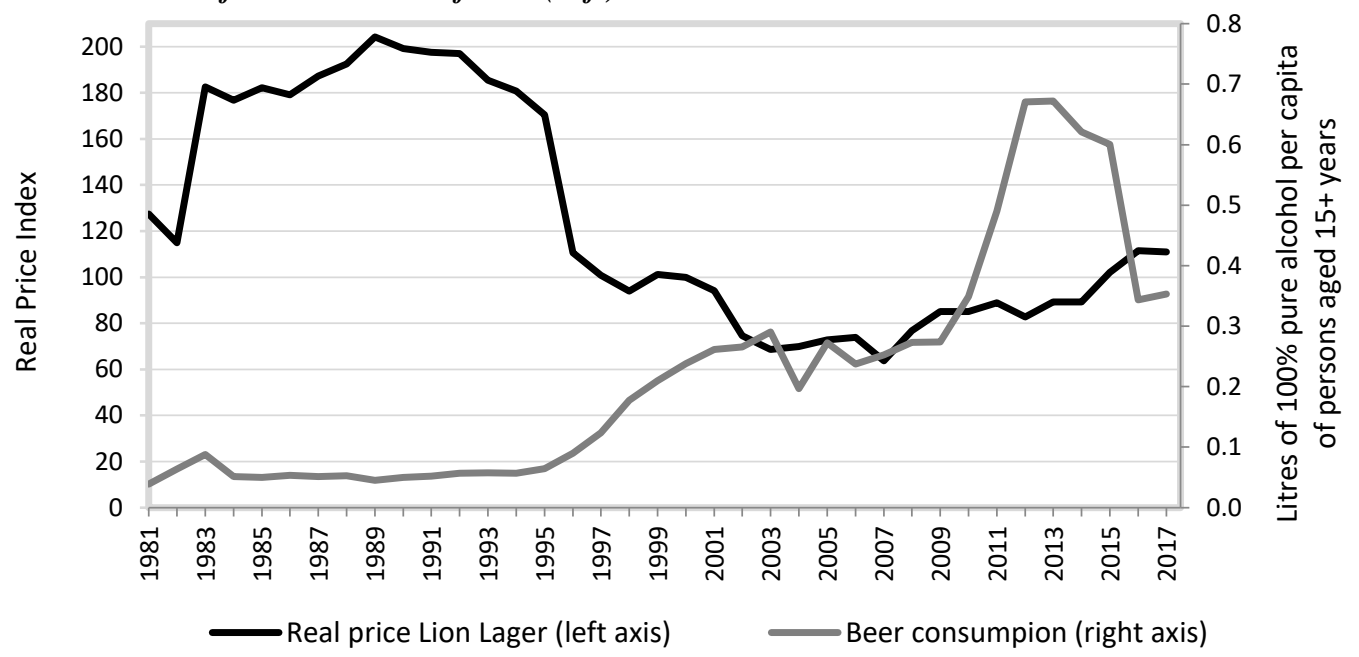

Note: Index year 2000=100; beer sales: in litres of 100\% pure alcohol per capita of persons aged 15+ years (right axis). Source: Sales: Excise Department of Sri Lanka (2017). Price: Department of Census and Statistics (2018b).

\section{Figure 4b}

Real Price Index of Arrack and Sales of Arrack 1981-2017

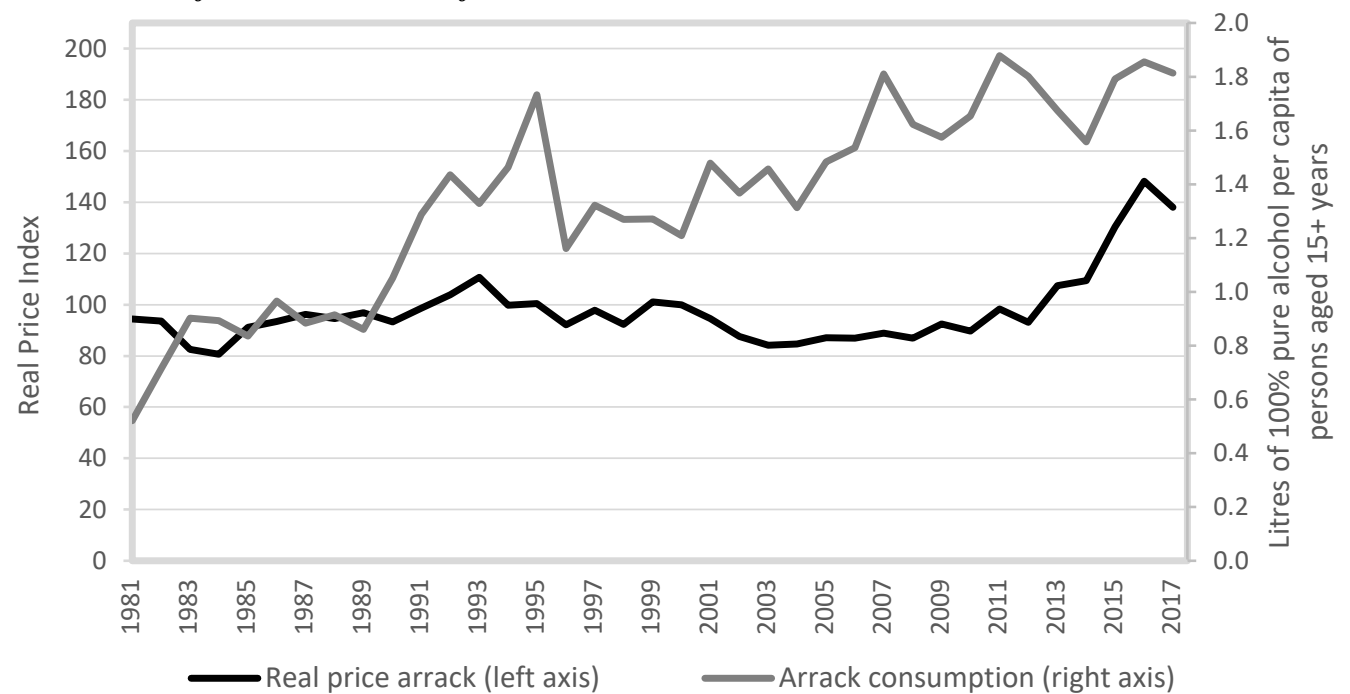

Note: Index year $2000=100$. Arrack sales: in litres of $100 \%$ pure alcohol per capita of persons aged $15+$ years (right axis). Sources: Sales: Excise Department of Sri Lanka (2017). Price: Department of Census and Statistics reports, various issues (e.g. 2018b) 


\section{Analytical Approach and Models Used}

The possible effects of changes in price and income on sales were analyzed by means of a time series analysis. In this study, the relationship between annual data points of price and income (independent variables) and sales (dependent variable) during the study period was analyzed (Yaffe, 2000). Additional analyses probed for possible cross-price elasticities, i.e., effects of changes in beer price on arrack sales and changes in arrack price on beer sales.

One of the complications often encountered is that the series are trending, which was the case in the data used. This may give rise to spurious relationships since the independent and dependent series may evolve in the same, or the opposite, direction without being causally related. If the time series are trending, the series are made stationary by means of differencing. This means that the relationship between yearly changes are analyzed instead of the raw data from the original series. This procedure reduces the risk for spurious relationships (McCleary \& Hay, 1980).

Another complication is the structure of the error term. This term includes, among other things, causal factors that are not included in the analysis. One of the prerequisites in a time series analysis is that this term should not have any structure, which means that possible explanatory variables that are left out can be expected to be autocorrelated. These complications are taken into account in the technique for time series analysis developed by Box and Jenkins (1976), called Auto Regressive Integrated Moving Average (ARIMA). Another feature of ARIMA is that the structure of the error term is estimated and incorporated into the model. This increases the reliability of the model estimates.

To study whether the variables were trended or not, in other words, to what extent they were integrated of the first order, a Dickey-Fuller test was conducted (Dickey, 2011). The results in Table 1 indicate that all variables used in the analysis were integrated of the first order. On this premise, tests for co-integration were conducted. The results from these tests show that the null hypothesis of no co-integration could not be rejected. Thus, the relation between the series should be calculated based on the differenced data.

Table 1

Augmented Dickey-Fuller Test (ADF) for Unit Root

\begin{tabular}{lcc}
\hline & ADF & P \\
\hline Beer sales & -1.12 & 0.70 \\
Beer price & -1.00 & 0.75 \\
Arrack sales & -2.18 & 0.21 \\
Arrack price & -0.29 & 0.93 \\
GDP & 2.87 & 1.00 \\
\hline
\end{tabular}

Log-log models were used, which means that both the output and the input series were logged according to the following specification for each of the two beverages: $\nabla L n S_{t}=a+\beta_{1} \nabla L n P_{t}+\beta_{2} \nabla L n I_{t}+\nabla N$

$S$ signifies the sales of arrack and beer respectively. $P$ and $I$ are real prices and income. The noise term $N$ includes other etiological factors. The structure of the noise term was estimated in terms of autoregressive (AR) and moving average (MA) parameters. An important criterion of model fit is that the residuals are white noise. This was determined by means of the Box-Ljung test (lag 5).

The operator $\nabla$ means that the series is differenced. The parameters for the price effect $\left(\beta_{1}\right)$ and the income effect $\left(\beta_{2}\right)$ give the percentage change in sales associated with a one percent change in price and income, respectively. The estimates are referred to as price and income elasticities.

\section{Results}

\section{Lag Structures}

Cross-correlations between the differenced series of sales on one hand, and price and income, respectively on the other hand were analyzed in order to detect any lagstructure in the relationship between the respective independent variables and sales (see Figure 5).

The cross-correlation between GDP and sales of beer shows an immediate correlation at lag 0 , which was expected, but also a correlation between GDP one and two years before year 0 (lag 1 and lag 2 ) and sales during year 0 . There was also a lagged correlation (lag 1) between beer price and beer sales and a weaker correlation at lag 0 .

The patterns of cross-correlations between GDP and sales of arrack, as well as between price of arrack and sales were very random. There was a minor positive correlation between price and sales at lag 0 , and a minor negative correlation at lag 1 . Regarding GDP, there were very small correlations at lag 0 and 1 .

Based on the cross-correlation analysis conducted, two models were used in the analysis for beer. One basic model included price and income changes in the same year as the changes in sales. The other model included a lag structure of the time series of both price and income. The lag structure used had the weight 0.5 for lag 0 and 0.5 for the changes in price and income at lag 1 . In the analysis of arrack, one basic model was used without lag structure.

\section{Price and Income Elasticities}

\section{Beer}

In the first model (Table 2), the estimate for price was 0.28 and for income 0.82 , but these estimates were not significant. This implies that changes in price and income had no significant effect on sales during the same year. However, in the second model (Table 3), the estimate for price was -1.05 , which was statistically significant $(p<0.001)$. This means that an increase in price (weighted) during year 0 and the year before had a negative effect on sales during year 0 . The income effect was 1.83 (not significant). 


\section{Figure 5}

Cross-Correlations of GDP and Price with Sales of Arrack and Beer, differenced time series

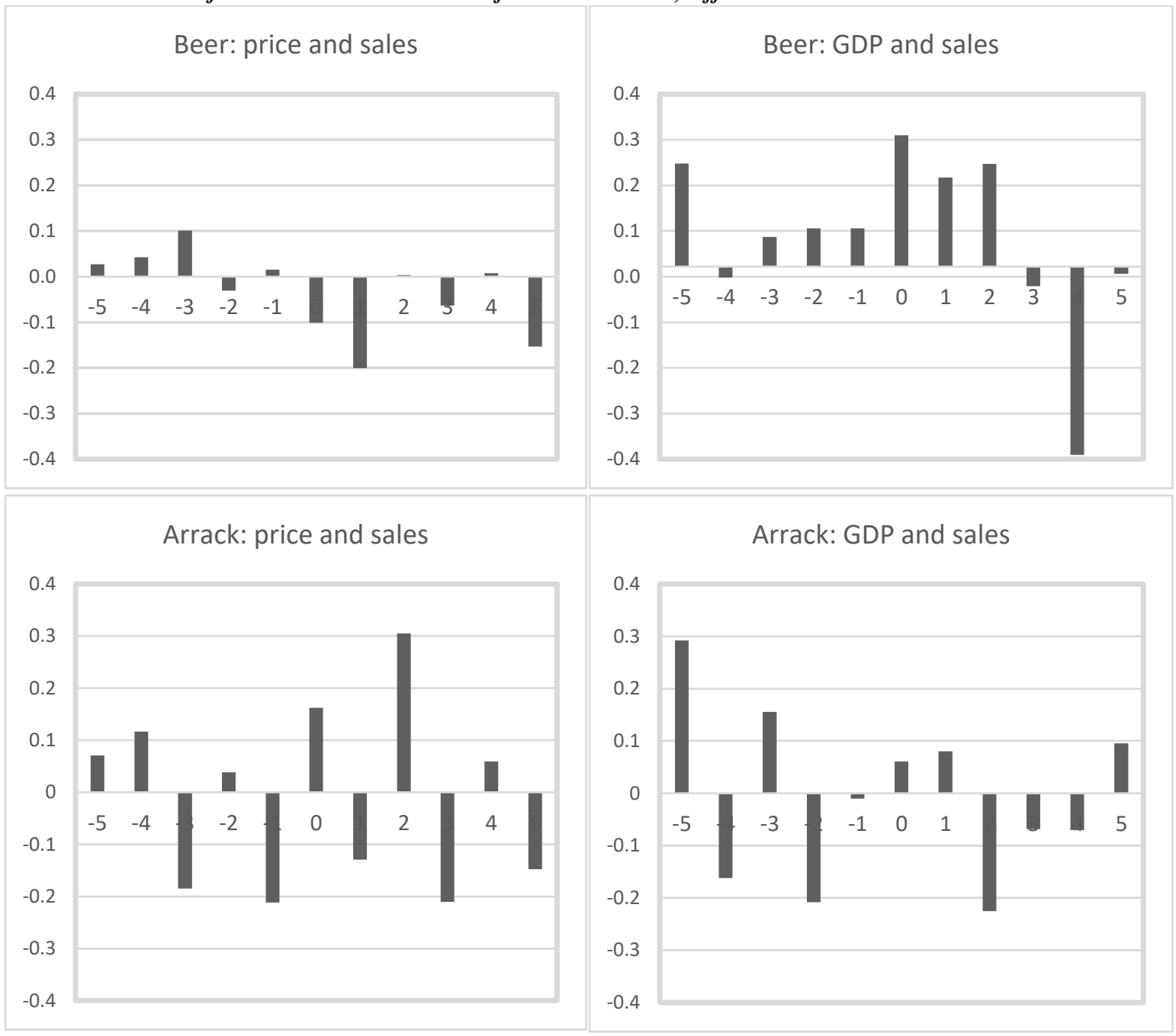

Note: Vertical axis (y-axis): correlation estimates; horizontal axis (x-axis): lagged years (from -5 to +5 )

Table 2

Model 1: The Effect of Changes in Price of Beer and Gross Domestic Product on Sales of Beer Using the ARIMA Log-Log Model

\begin{tabular}{lccc}
\hline Variables & Estimates & SE & P \\
\hline Beer price & -0.28 & 0.24 & 0.261 \\
GDP & 0.82 & 1.86 & 0.661 \\
Constant & 0.03 & 0.09 & 0.758
\end{tabular}

$\mathrm{Q}^{\mathrm{a}}(5)=1.22 ; \mathrm{P}=0.94$

${ }^{\mathrm{a}} \mathrm{Q}=$ Box-Ljung test of residuals, (lag 5)

\section{Arrack}

In the analysis regarding the sales of arrack, the estimate for price was -0.14 and for income 0.42 (Table 4). However, these estimates were not significant. Alternative lag structures for both price and income were tested but gave similar results.
Table 3

Model 2: The Effect of Changes in Price of Beer and Gross Domestic Product, with Lag Structure, on Sales of Beer Using an ARIMA Log-Log Model

\begin{tabular}{lccc}
\hline Variables & Estimates & SE & P \\
\hline Beer price, lag & $-1.05^{* * *}$ & 0.32 & 0.001 \\
structure & & & \\
GDP, lag structure & 1.83 & 1.63 & 0.263 \\
Constant & -0.03 & 0.09 & 0.780
\end{tabular}

$\mathrm{Q}^{\mathrm{a}}(5)=3.40 ; \mathrm{P}=0.64$

${ }^{\mathrm{a}} \mathrm{Q}=$ Box-Ljung test of residuals, (lag 5)

$* \mathrm{p}<0.05, * * \mathrm{p}<0.01, * * * \mathrm{p}<0.001$

Cross-price elasticities were estimated as well. A significant effect of beer price changes, without a lag structure, was found on arrack sales, implying that arrack sales increase when the tax on beer increases. The crossprice effect was $0.35(\mathrm{p}=0.01)$. No cross-price effect was found from changes in the price of arrack on sales of beer. 
Table 4

Model 1: The Effect of Changes in Price of Arrack and Gross Domestic Product, on Sales of Arrack Using an ARIMA Log-Log Model.

\begin{tabular}{lccl}
\hline Variables & Estimates & SE & P \\
\hline Arrack price & 0.14 & 0.35 & 0.695 \\
GDP & 0.42 & 0.79 & 0.593 \\
Constant & 0.02 & 0.03 & 0.580 \\
& & & \\
$\mathrm{Q}^{\mathrm{a}}(5)=8.60 ;$ & & \\
$\mathrm{P}=0.126$ & & & \\
${ }^{\mathrm{a}} \mathrm{Q}=$ Box-Ljung test of residuals, (lag 5) &
\end{tabular}

\section{Discussion}

The present analysis did not reveal any immediate significant effects of price or income on sales, but the coefficients were in the expected direction. However, when the price series of beer was used with a lag structure, a significant effect on sales was found. No similar time lag was found for arrack prices, but changes in the price of beer, without a lag structure, had a significant effect on arrack sales. The interpretation of these results, however, is not given. Below we shed light on some factors within the Sri Lankan alcohol culture that might contribute to a better understanding of the findings.

\section{Traditional Versus Modern Alcoholic Beverages}

Arrack is the traditional beverage and by far the most consumed. Beer, on the other hand, is a rather new beverage in terms of popularity and perhaps associated with a more modern lifestyle. Therefore, the beverages may appeal to different segments of the population whose price sensitivity may vary.

The per capita alcohol consumption is low in Sri Lanka and most people drink rather infrequently. Given that beer is a commodity which is purchased rather infrequently, it is not unlikely that the full reaction to price changes on beer materializes over time, in this case during the current year and the year after.

\section{High Prices and Few Regular Drinkers}

Sri Lankan alcohol prices are high in relative terms, especially compared to high-income countries. Roughly $8 \%$ of the total population, mostly men, are weekly consumers (Ministry of Health, Nutrition and Indigenous Medicine, 2015). The results on arrack suggest that this group did not react to price changes that have occurred during the study period. Other studies from high-income countries with high alcohol taxation do find significant price elasticities on most beverages, suggesting that heavy drinkers are sensitive to price as well (Andersson, 2009; Elder et al., 2010).

The lack of effect of changes in the price of arrack on sales of arrack does not mean that the level of these high taxes does not have a dampening effect on sales, only that price changes at this tax level do not seem to have an effect.
Interestingly, changes in the price of beer had a significant effect on the sales of arrack. This implies that tax increases on the two beverages should take place simultaneously in order to prevent substitution.

\section{Other Characteristics of the Drinking Culture}

In many cultures, vacations and especially holidays (bank holidays) are associated with rather heavy drinking (Leifman \& Gustafsson, 2002). In Sri Lanka, however, sales are banned on religious holidays (Poya days), which occur more than once a month. This signifies a strong religious or moral component attached to drinking which could be an explanation for our findings. Alcohol is definitely not an ordinary commodity and the demand may not react as expected to price changes.

\section{The Validity of the Data}

The sales data are generally considered to be of high quality. The sales and production time series trends on arrack and beer reveal strong correlations. This strengthens the view of the sales data as being trustworthy.

There were two indicators of income available, GDP and the mean income per capita (based on surveys). However, GDP was the only measure with annual data points and was therefore used in the analyses. The two measures showed similar development until 2007, but thereafter the GDP increased to a larger extent than the mean income. This discrepancy should be taken into account in the interpretation of the results.

The northern districts were the most affected by the war and some of them have missing data from several years. We therefore performed additional analyses without the northern districts. The findings were very similar to those presented above. Since the consumer price index as well as the actual prices on arrack and beer were based on Colombo figures, we also made separate analyses on this district only. Again, the findings were similar.

Beer is sold at only two strengths: $4.8 \%$ and $8.8 \% \mathrm{ABV}$. Data on production reveal that $83 \%$ of the beer sold during 2008-2018 was the stronger type, but the beer prices used were based on the weaker beer. However, before 1999 only beer containing $4.8 \% \mathrm{ABV}$ was available. No price data are available for the stronger beer, but taxation data for 1999-2017 for both types of beer show almost identical trends. The changes in beer taxation always occur simultaneously. Thus, a price change on Lion Lager is most likely a valid indicator of changes in beer prices in general.

There is a general belief that tourists' consumption will inflate the estimated actual consumption by Sri Lankan inhabitants, based on recorded sales. However, the tourist consumption has been estimated to account for only 1-3\% of recorded consumption. (Leifman, 2019). 


\section{Conclusion}

Sales of alcohol in Sri Lanka are not affected by price changes to the same extent as in high-income countries. Why sales are not affected by traditional economic theory in the same manner begs further research. Most likely, the explanations will be found in the very different drinking culture compared to that in high-income countries, with a moral and religious condemnation of drinking in Sri Lanka. The high price-level of alcoholic beverages implies that these beverages could be seen as commodities mostly affordable by rich inhabitants and most drinkers consume alcohol rather infrequently. The amount of unrecorded alcohol may play an important role as well. However, the high price level per se does in all probability restrict the availability to alcohol among low- and middleincome segments of the population.

\section{Acknowledgements}

The authors would very much like to thank Thirupathy Suveendran at the WHO office in Colombo, Palitha Abeykoon at National Authority on Tobacco \& Alcohol (NATA), and the Alcohol and Drug Information Centre (ADIC) in Colombo. We would also like to thank Thor Norström, professor at Stockholm University and assistant professor Mats Ramstedt at CAN for valuable comments.

\section{References}

Anderson, P., Chisholm, D., \& Fuhr, D. (2009). Effectiveness and cost-effectiveness of policies and programmes to reduce the harm caused by alcohol. Lancet, $\quad 373, \quad 2234-2246$. https://doi.org/10.1016/S0140-6736(09)60744-3

Babor, T., Caetano, R., Casswell, S., Edwards, G., Giesbrecht, N., Graham, K., ... Rossow, I. (2010). Alcohol: No ordinary commodity. Research and public policy, 2nd ed. Oxford, England: Oxford University Press.

Box, G. E. P., \& Jenkins, G. M. (1976). Time Series Analyses: Forecasting and Control, Revised Edition. San Francisco: Holden Day.

Department of Census and Statistics. (2018a). Household Income and Expenditure Survey 2016. HIES Final Report 2016. Ministry of National Policies and Economic Affairs. Colombo, Sri Lanka.

Department of Census and Statistics. (2018b). Inflation and Prices. Retrieved from: http://www.statistics.gov.lk/page.asp?page=Inflation and Prices

Dickey, D. G. (2011). Dickey-Fuller Tests. In M. Lovric (Ed.), International Encyclopedia of Statistical Science (pp. 385-388). Berlin, Heidelberg: Springer Berlin Heidelberg.

Elder, R. W., Lawrence, B., Ferguson, A., Naimi, T. S., Brewer, R. D., Chattopadhyay, S. K., Toomey, T. L., Fielding, J. E., \& Task Force on Community Preventive Services (2010). The effectiveness of tax policy interventions for reducing excessive alcohol consumption and related harms. American Journal of Preventive Medicine, 38(2), 217-229. https://doi.org/10.1016/j.amepre.2009.11.005

Excise Department of Sri Lanka (2017). Excise Department Performance Reports.
Excise Notification (1951) No. 417 of Ceylon Government Gazette No 100266 of 5.7.1951.

Excise Notification (1955) No. 447 of 29.4.1955: Section 12.

Excise Notification (1979) No. 666 of 1979 of the Extraordinary Gazette.

Kumar, S. (2017). Price elasticity of alcohol demand in India. Alcohol and Alcoholism, 52(3) 390-395. https://doi.org/10.1093/alcalc/agx001

Leifman, H. (2019). Trends and patterns of alcohol consumption in Sri Lanka 1981-2017: Analyses of sales and survey data. Alcohol and Drug Information Centre (ADIC), National Authority on Tobacco and Alcohol (NATA) and The Swedish Council for Information on Alcohol and Other Drugs (CAN). Sri Lanka 2018.

Leifman, H. \& Gustafsson, N-K. (2004). Drickandets temporala struktur: Analyser av alkoholkonsumtionens och berusningsdrickandets månatliga variationer $\mathrm{i}$ Sverige. (The temporal structure of drinking: Analyses of monthly variations in drinking and binge drinking in Sweden. Nordisk Alkohol- och Narkotikatidskrift, 21(1), 5-21. https://doiorg/10.1177/145507250402100105

McCleary, R. \& Hay, R. (1980). Applied Time Series Analysis for the Social Sciences. Thousand Oaks, CA, Sage Publications.

Ministry of Health, Nutrition and Indigenous Medicine (2015). Non Communicable Disease Risk Factor Study Sri Lanka 2015: The STEPS survey. Ministry of Health, Nutrition and Indigenous Medicine. Colombo, Sri Lanka.

Nugawela, M.D., Lewis, S., Szatkowski L. \& Langley, T. (2017). Rapidly increasing trend of recorded alcohol consumption since the end of the armed conflict in Sri Lanka. Alcohol and Alcoholism, 52(5), 550-556. https://doi.org/10.1093/alcalc/agx044

Selvanathan, S., \& Selvanathan, E.A. (2005). The demand for alcohol, tobacco and marijuana: International evidence. Burlington, VT: Ashgate Publishing.

Sornpaisarn, B., Shield, K., Cohen, J., Schwartz, R., \& Rehm, J. (2013). Elasticity of alcohol consumption, alcohol-related harms, and drinking initiation in lowand middle-income countries: A systematic review and meta-analysis. International Journal of Alcohol and Drug Research, 2(1), 45-58. https://doi.org/10.7895/ijadr.v2i1.50

UNDP (2012). United Nations Development Programme (UNDP). Retrieved from: http://www.lk.undp.org/content/srilanka/en/home/co untryinfo/.

Wagenaar, A. C., Tobler, A. L., \& Komro, K. A. (2010). Effects of alcohol tax price policies on morbidity and mortality: A systematic review. American Journal of Public Health, 100(11), 2270-2278. https://doi.org/10.2105/AJPH.2009.186007

WHO (2014). Global status report on alcohol and health 2014. World Health Organization

WHO (2018). Global status report on alcohol and health 2018. World Health Organization

World Bank DataBase (2018). Retrieved from: https://data.worldbank.org/country/srilanka?view=chart

Yaffe R.A. (2000). Introduction to time series analysis and forecasting: With applications of SAS and SPSS. San Diego, CA: London: Academic Press Inc. 